\title{
Interleukin-10 promoter polymorphisms associated with susceptibility to lumbar disc degeneration in a Chinese cohort
}

\author{
W.P. Lin, J.H. Lin, X.W. Chen, C.Y. Wu, L.Q. Zhang, \\ Z.D. Huang and J.M. Lai \\ Department of Orthopedics, The First Affiliated Hospital, \\ Fujian Medical University, Fuzhou, Fujian, P.R. China \\ Corresponding author: J.H. Lin \\ E-mail: jianhua0918@126.com
}

Genet. Mol. Res. 10 (3): 1719-1727 (2011)

Received January 21, 2011

Accepted July 20, 2011

Published August 16, 2011

DOI http://dx.doi.org/10.4238/vol10-3gmr1283

\begin{abstract}
We investigated a possible association between interleukin (IL)-10 single nucleotide polymorphisms (SNPs) and susceptibility to and severity of lumbar disc degeneration (LDD) in a Chinese cohort of 320 patients with LDD and 269 gender- and age-matched controls. The degree of disc degeneration was determined by magnetic resonance imaging using Schneiderman's classification. Genetic analysis of IL-10 promoter polymorphisms (at $-1082 \mathrm{~A} / \mathrm{G},-819 \mathrm{~T} / \mathrm{C}$, and -592 A/C) was carried out by PCR-RFLP. A total of 134 herniated lumbar intervertebral discs were collected during surgery for IL-10 mRNA detection. For SNPs at -592 , the A allele and AA genotype frequencies were significantly higher in LDD patients than in controls. Similarly, the AA genotype and A allele frequencies at -1082 were significantly higher in cases than in controls. Among the LDD subjects, carriers of AA at -592 and GG at -1082 had significantly lower mean IL-10 mRNA expression than the other two genotypes. The SNPs at each locus were not significantly associated with severity grade in the LDD patients. Logistic regression analyses showed that the AA at -1082, AA at -592 , and IL-10 mRNA expression level were independent risk factors for
\end{abstract}


LDD. We conclude that the IL-10 SNPs at $-1082 \mathrm{~A} / \mathrm{G}$ and $-592 \mathrm{~A} / \mathrm{C}$ as well as IL-10 mRNA in the herniated lumbar intervertebral discs are associated with susceptibility to LDD in this Chinese cohort, but not with disease severity.

Key words: Lumbar disc degeneration; Polymorphisms; Interleukin-10; Susceptibility

\section{INTRODUCTION}

Lumbar disc degeneration (LDD) is a process that begins early in life, contributing to the development of low back pain and unilateral leg pain in humans. LDD is a consequence of a variety of intrinsic and extrinsic factors, and the etiology of LDD remains poorly understood. The environmental factors, e.g., age, gender, smoking, overweight, exposure to vibration, etc., may contribute to LDD (Hassett et al., 2003; Iguchi et al., 2003; Pye et al., 2006). In addition, the role of hereditary factors in LDD was documented as well. Several predisposing genes have been identified in LDD (Sambrook et al., 1999; Battie et al., 2004; Valdes et al., 2005).

Recently, the role of inflammation in the process of LDD has attracted much interest. Inflammatory cells and mediators have been observed in lumbar disc herniation tissue removed during disc prolapse surgery (Kawaguchi et al., 2001; Scuderi et al., 2006). Infiltration of inflammatory cells, such as macrophages, neutrophils, lymphocytes, and multinucleated giant cells, was observed in lumbar intervertebral discs, suggesting that local inflammation was involved in the degenerative process of the intervertebral disc (Woertgen et al., 2000; Kawaguchi et al., 2001, 2002). A variety of inflammatory mediators, including nitric oxide, matrix metalloproteinases (MMP), prostaglandin E2 (PGE2), tumor necrosis factor alpha (TNF- $\alpha$ ), and interleukins (IL), have been implicated in the degeneration of lumbar intervertebral discs (Ahn et al., 2002; Igarashi et al., 2004).

IL-10 is a $36-\mathrm{kDa}$ homodimeric anti-inflammatory cytokine, which is produced primarily by monocytes and lymphocytes. It is mainly expressed in monocytes and type 2 T helper cells, mast cells, and CD4(+)/CD25(+)/Foxp3(+) regulatory T cells (Lalani et al., 1997). This cytokine has pleiotropic effects in immune regulation and inflammation, including inhibiting the synthesis of proinflammatory cytokines, e.g., TNF- $\alpha$, IL-1, IL-6, insulin growth factor (IGF), and transforming growth factor beta (TGF- $\beta$ ) (Tworek and Kuna, 2005).

The IL-10 promoter is highly polymorphic containing several polymorphisms, which have been described in the promoter region of IL-10 and could affect transcriptional regulation of this gene (Ma et al., 2005). Three single nucleotide polymorphisms (SNPs), a G to A substitution at position -1082 , a C to $\mathrm{T}$ at -819 , and a $\mathrm{C}$ to $\mathrm{A}$ at -592 , were identified in the promoter regions of IL-10. Several previous reports demonstrated that these SNPs induce quantitative differences in IL-10 transcription, and thus affect IL-10 protein expression level (Reuss et al., 2002; Kurreeman et al., 2004). IL-10 SNPs have been demonstrated to play an important role in association with various diseases.

To date, an association between the IL-10 SNPs and LDD has not been previously documented. In this study, we performed a case-control study to explore the possible role of IL-10 SNPs in determining the susceptibility and severity of LDD in a Chinese cohort. 


\section{MATERIAL AND METHODS}

\section{Subject enrollment}

The study examined 320 patients with LDD and 269 gender- and age-matched controls from September 2006 to August 2010 in our hospital. All patients had received MRI evaluation, and all controls were evaluated by CT or MRI. The diagnosis was confirmed by two orthopedic surgeons specialized in spinal diseases, who were unaware of the study design. The grade of disc degeneration was determined by MRI using Schneiderman's classification (Matsui et al., 1998). Exclusion criteria included: a) subject with autoimmune disease and inflammatory disease, b) severe degenerative disc disease with collapsed intervertebral space, c) previous surgical treatment in the lumbar spine, d) severe osteoporosis, and e) segmental instability.

The information concerning gender, age and body mass index (BMI), smoking status, and family history of LDD was collected from all participants. The Ethics Committee of our school approved the study. Informed consent was obtained from all participants.

\section{Genetic polymorphism analysis}

Fasting peripheral blood was drawn from all participants. Genomic DNA was extracted from peripheral blood using the Qiagen DNA Isolation kit (Qiagen GmbH, Hilden, Germany). IL-10 promoter polymorphisms were identified by polymerase chain reaction amplification and restriction fragment length polymorphism analysis (PCR-RFLP). The primer sequence of each SNPs and the restriction enzymes (all from New England Biolabs, MA, USA) are listed in Table 1. Each PCR was performed in a GeneAmp PCR System 9600 thermocycler (Applied Biosystems, Foster City, CA, USA) at a final volume of $25 \mu \mathrm{L}$ (containing 5 pmol of each primer, $50 \mathrm{ng}$ genomic DNA, $1.5 \mathrm{mM} \mathrm{MgCl}, 5 \mu \mathrm{M}$ dNTPs, and 1 $\mathrm{U}$ Taq DNA polymerase in PCR buffer containing $10 \mathrm{mM}$ Tris- $\mathrm{HCl}$ and $50 \mathrm{mM} \mathrm{KCl}$ ). PCR cycles used were as follows: $95^{\circ} \mathrm{C}$ for $5 \mathrm{~min}$; 35 cycles of denaturing at $95^{\circ} \mathrm{C}$ for $40 \mathrm{~s}$, annealing at the indicated temperature for $1 \mathrm{~min}$, extension at $72^{\circ} \mathrm{C}$ for $40 \mathrm{~s}$, and a single final extension at $72^{\circ} \mathrm{C}$ for $10 \mathrm{~min}$. After amplification, all products were digested with restriction endonucleases, and separated by electrophoresis on a $10 \%$ polyacrylamide gel stained with silver nitrate for visualization. To confirm the genotyping results, 10\% PCR-amplified DNA samples were examined by DNA sequencing.

\begin{tabular}{|c|c|c|c|c|}
\hline Polymorphism & Primer sequence & Annealing temperature & Restriction enzyme & Allele size \\
\hline IL-10 -1082 G/A & $\begin{array}{l}\text { 5'-CTCGCTGCA ACCCAACTGGC-3' } \\
\text { 5'-TCTTACCTATCCCTACTTCC-3' }\end{array}$ & $58^{\circ} \mathrm{C}$ & $M n l \mathrm{I}$ & $\begin{array}{l}\text { A: } 139 \mathrm{bp} \\
\text { G: } 106,33 \mathrm{bp}\end{array}$ \\
\hline IL-10 -819 C/T & $\begin{array}{l}\text { 5'-TCATTCTATGTGCTGGAGATGG-3' } \\
\text { 5'-TGGGGGAAGTGGGTAAGAGT-3' }\end{array}$ & $59^{\circ} \mathrm{C}$ & MaeIII & $\begin{array}{l}\text { C: } 125,84 \mathrm{bp} \\
\text { T: } 209 \mathrm{bp}\end{array}$ \\
\hline IL-10 -592 C/A & $\begin{array}{l}\text { 5'-GTGAGCACTACCTGACTAGC-3' } \\
\text { 5'-CCTAGGTCACAGTGACGTGG-3' }\end{array}$ & $58^{\circ} \mathrm{C}$ & $R s a \mathrm{I}$ & $\begin{array}{l}\text { C: } 412 \mathrm{bp} \\
\text { A: } 175,237 \mathrm{bp}\end{array}$ \\
\hline
\end{tabular}




\section{Real-time PCR of IL-10 mRNA}

A total of 134 herniated lumbar intervertebral discs were collected during surgery. Cytokine gene expression was determined by the semiquantitative PCR method. With cDNA as the template, PCR was carried out with primers for IL-10. The procedure conditions were pre-denaturation at $95^{\circ} \mathrm{C}$ for $7 \mathrm{~min} ; 35$ cycles of denaturation at $94^{\circ} \mathrm{C}$ for $60 \mathrm{~s}$, annealing at $64^{\circ} \mathrm{C}$ for $30 \mathrm{~s}$, extension at $72^{\circ} \mathrm{C}$ for $60 \mathrm{~s}$, and a final cycle of 10 min more at $72^{\circ} \mathrm{C}$. Each time, the $\beta$-actin was amplified to detect the cytokine quantity by ratio of the cytokine to $\beta$-actin.

\section{Statistical analysis}

For each SNP, the chi-square test was performed to assess Hardy-Weinberg equilibrium and association between the LDD case and control groups based on allelic and genotypic frequencies. Characteristics of LDD subjects and controls were compared by the chi-square or the Student $t$-test according to the variable types. Binary logistic regression test was performed to determine the risk factor for LDD. The odds ratios (OR) and $95 \%$ confidence intervals (CIs) were calculated with adjustment for age, gender, smoking status, and other clinical data. Differences were considered to be significant when $\mathrm{P}$ was less than 0.05 . The analyses were performed with the SPSS software (Statistical Package for the Social Sciences, version 16.0, SPSS Inc., Chicago, IL, USA).

\section{RESULTS}

The characteristics of LDD subjects and controls are shown in Table 2. Gender, age and BMI were similar between the two groups. Smoking status was more common in LDD subjects than in controls ( 39.9 vs $23.5 \%, \mathrm{P}=0.043)$. The incidence of positive family history was markedly higher in the LDD group than in controls $(16.8$ vs $7.1 \%, \mathrm{P}<0.001)$.

Table 2. Characteristics of subjects.
\begin{tabular}{lccr}
\hline Variables & Case (N =320) & Control (N=269) & P \\
\hline Age (means \pm SD) & $46.3 \pm 8.4$ & $46.5 \pm 9.7$ & 0.584 \\
Gender (male, \%) & 45.9 & 46.8 & 0.743 \\
BMI (means \pm SD) & $23.9 \pm 2.5$ & $23.6 \pm 2.2$ & 0.772 \\
Smoking (\%) & 39.9 & 23.5 & 0.043 \\
Family history (\%) & 16.8 & 7.1 & $<0.001$ \\
Grade & 58 & & \\
I & 131 & & \\
II & 69 & & \\
III & 62 & & \\
IV & & & \\
BMI = body mass index. & & &
\end{tabular}

The allele frequencies and genotype distribution of all SNPs in LDD cases and controls are summarized in Table 3. The genotype distributions for each SNP were in HardyWeinberg equilibrium. For SNPs at -819 , there was no statistically significant difference in the distribution of alleles and genotypes between patients and controls $(\mathrm{P}=0.153$, and $\mathrm{P}=0.517$, respectively). 
Table 3. Allele and genotype distribution of the three SNPs in lumbar disc degeneration cases and controls.

\begin{tabular}{|c|c|c|c|c|c|c|}
\hline & & Case $(\mathrm{N}=320)$ & Control $(\mathrm{N}=269)$ & Chi-square & d.f. & $\mathrm{P}$ \\
\hline \multirow[t]{5}{*}{-819} & $\mathrm{CC}$ & $104(32.5 \%)$ & $108(40.1 \%)$ & 3.15 & 2 & 0.153 \\
\hline & $\mathrm{CT}$ & $136(42.5 \%)$ & $99(36.8 \%)$ & & & \\
\hline & TT & $80(25.0 \%)$ & $62(23.0 \%)$ & & & \\
\hline & $\mathrm{C}$ & $344(53.75 \%)$ & $315(58.55 \%)$ & 0.5 & 1 & 0.517 \\
\hline & $\mathrm{T}$ & $296(46.25 \%)$ & $223(41.45 \%)$ & & & \\
\hline \multirow[t]{5}{*}{-592} & AA & $150(46.9 \%)$ & $89(33.1 \%)$ & 11.5 & 2 & 0.003 \\
\hline & $\mathrm{AC}$ & $113(35.3 \%)$ & $119(44.2 \%)$ & & & \\
\hline & $\mathrm{CC}$ & $57(17.8 \%)$ & $61(22.7 \%)$ & & & \\
\hline & A & $413(64.5 \%)$ & 297 (48.5\%) & 10.6 & 1 & 0.001 \\
\hline & $\mathrm{C}$ & $227(35.5 \%)$ & $241(51.5 \%)$ & & & \\
\hline \multirow[t]{5}{*}{-1082} & GG & $118(36.9 \%)$ & $122(45.4 \%)$ & 6.2 & 2 & 0.045 \\
\hline & GA & $113(35.3 \%)$ & $93(34.6 \%)$ & & & \\
\hline & AA & $89(27.8 \%)$ & $54(20.1 \%)$ & & & \\
\hline & G & $349(54.5 \%)$ & $337(62.6 \%)$ & 5.7 & 1 & 0.003 \\
\hline & A & $291(45.5 \%)$ & $201(37.4 \%)$ & & & \\
\hline
\end{tabular}

Data are reported as number with percent in parentheses. d.f. $=$ degrees of freedom.

For SNPs at -592 , allele analysis revealed that the A allele frequency was $64.5 \%$ in LDD patients and $48.5 \%$ in controls $(P=0.001)$. A significant difference was observed in the genotype distribution between cases and controls. AA prevalence was markedly higher in cases than in controls ( 46.9 vs 33.1\%, $\mathrm{P}=0.003$ ). Similar to SNPs at -592 , significant differences were observed in the genotype distribution at -1082 between case and control groups. The number of individuals with the AA genotype was significantly higher in cases than in controls $(27.8$ vs $20.1 \% \mathrm{P}=0.045)$. The A allele frequency was markedly higher in cases than in controls (45.5 vs $37.4 \%, \mathrm{P}=0.003)$.

Among the LDD subjects, IL-10 mRNA expression in the herniated lumbar intervertebral discs collected during surgery was analyzed according to IL-10 genotypes. Figure 1 reveals that the carriers of AA at -592 and AA at -1082 had significantly lower mean IL10 mRNA expression than the other two respective genotypes. IL-10 mRNA expression was similar among the carriers with SNPs at -819 .

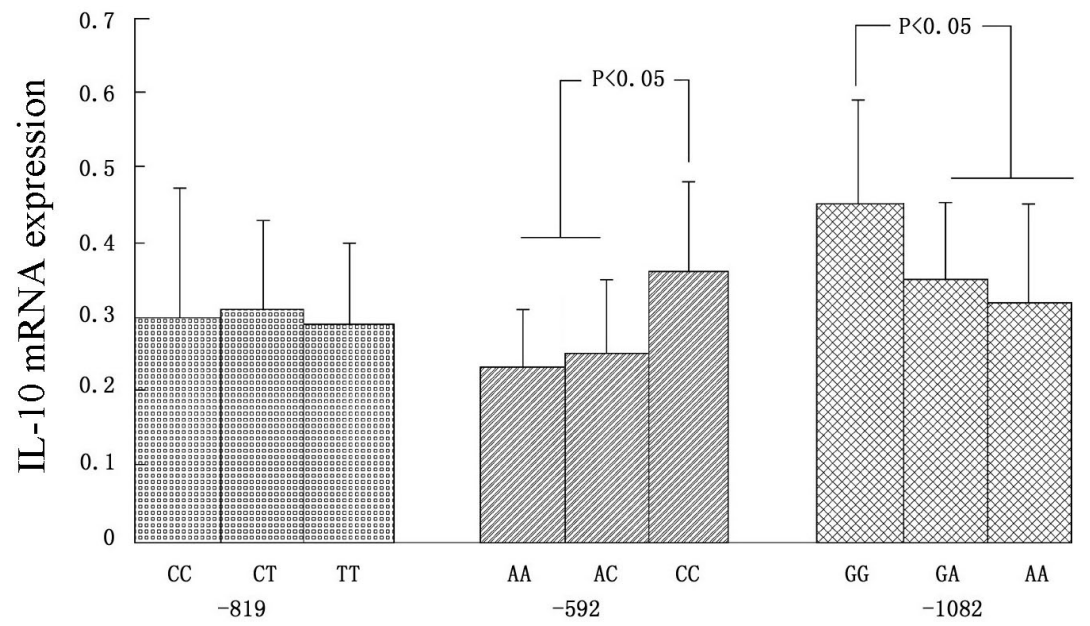

Figure 1. IL-10 mRNA expression in the herniated lumbar intervertebral discs according to IL-10 SNPs at 3 gene loci. 
Among the LDD subjects, the severity of LDD was analyzed according to IL-10 genotypes. Table 4 reveals that the genotype distributions for SNPs at each locus among subjects with different severity grades were similar (all $\mathrm{P}>0.05$ ).

\begin{tabular}{|c|c|c|c|c|c|c|c|c|}
\hline Variable & & $\begin{array}{c}\text { Grade I } \\
(\mathrm{N}=58)\end{array}$ & $\begin{array}{c}\text { Grade II } \\
(\mathrm{N}=131)\end{array}$ & $\begin{array}{l}\text { Grade III } \\
(\mathrm{N}=69)\end{array}$ & $\begin{array}{l}\text { Grade IV } \\
(\mathrm{N}=62)\end{array}$ & Chi-square & d.f. & $\mathrm{P}$ \\
\hline \multirow[t]{3}{*}{-819} & $\mathrm{CC}$ & 31 (53.4\%) & $65(49.6 \%)$ & $32(46.4 \%)$ & $22(35.5 \%)$ & 5.6 & 6 & 0.467 \\
\hline & CT & $18(31.0 \%)$ & $42(32.1 \%)$ & $27(39.1 \%)$ & $26(41.9 \%)$ & & & \\
\hline & TT & $9(15.5 \%)$ & $24(18.3 \%)$ & $10(14.5 \%)$ & $14(22.6 \%)$ & & & \\
\hline \multirow[t]{3}{*}{-592} & AA & $18(31.0 \%)$ & $38(29.0 \%)$ & $22(31.9 \%)$ & $26(41.9 \%)$ & 6.2 & 6 & 0.396 \\
\hline & $\mathrm{AC}$ & $21(36.2 \%)$ & $63(48.1 \%)$ & $30(43.5 \%)$ & $22(35.5 \%)$ & & & \\
\hline & $\mathrm{CC}$ & $19(32.8 \%)$ & $30(22.9 \%)$ & $17(24.6 \%)$ & $14(22.6 \%)$ & & & \\
\hline \multirow[t]{3}{*}{-1082} & GG & $25(43.1 \%)$ & $43(32.8 \%)$ & $28(40.6 \%)$ & $22(35.5 \%)$ & 3 & 6 & 0.774 \\
\hline & GA & $22(37.9 \%)$ & $55(42.0 \%)$ & $29(42.0 \%)$ & 27 (43.5\%) & & & \\
\hline & AA & $11(19.0 \%)$ & $33(25.2 \%)$ & $12(17.4 \%)$ & $13(21.0 \%)$ & & & \\
\hline
\end{tabular}

Data are reported as number with percent in parentheses. d.f. $=$ degrees of freedom.

We further performed binary logistic regression to analyze the possible risk factors for occurrence of LDD. The clinical data, namely age, gender, BMI, family history, smoking, and the IL-10 mRNA expression level as well as the SNPs at 3 loci of IL-10 gene were taken as covariates. Our results showed that AA at -1082, AA at -592, IL-10 mRNA expression level, smoking, and family history were independent risk factors for LDD (Table 5).

Table 5. Risk factor analysis for lumbar disc degeneration with binary logistic regression.

\begin{tabular}{llll}
\hline Risk factor & OR & $95 \%$ CI & P \\
\hline AA at -1082 & 1.34 & $1.12-3.03$ & 0.032 \\
AA at -592 & 1.68 & $1.23-3.46$ & 0.026 \\
IL-10 mRNA & 2.33 & $1.67-4.42$ & 0.014 \\
Smoking & 1.34 & $1.11-2.45$ & 0.043 \\
Family history & 1.58 & $1.21-3.17$ & 0.031 \\
\hline
\end{tabular}

$\mathrm{OR}=$ odds ratio $; 95 \% \mathrm{CI}=$ confidence interval at 95\%; IL-10 = interleukin 10 .

\section{DISCUSSION}

In the present study, we analyzed the association between 3 SNPs of the IL-10 promoter $(-1082 \mathrm{~A} / \mathrm{G},-819 \mathrm{~T} / \mathrm{C}$, and $-592 \mathrm{~A} / \mathrm{C})$ as well as the IL-10 mRNA expression, and the incidence and severity of LDD in a Chinese cohort. Significant differences were observed in the allele frequencies and genotype distributions for the IL-10 SNPs at -1082 and -592 between LDD cases and controls. The SNPs at -1082 and -592 influenced the IL-10 mRNA expression level. Logistic regression revealed that AA at 1082, AA at 592 and IL-10 mRNA expression level were independent risk factors for LDD.

Previous studies provided evidence that interleukins may participate in local inflammation of the intervertebral disc, and thus contribute to the development of LDD. Significantly increased expression of IL-1, IL-2, IL-4, and IL-12 as well as TNF- $\alpha$ was found in disc samples in patients compared to controls (Ahn et al., 2002; Igarashi et al., 2004; Akyol et al., 2010). IL-8 has been proposed to participate in the pathomechanism of nerve root inflamma- 
tion in lumbar disc herniations and to be associated with the development of radicular pain (Akyol et al., 2010).

Previous studies also suggest an association between IL-10 and LDD. Immunohistochemical analysis indicates that there is an increase in IL-10 protein expression in late intervertebral disk disease compared with controls. In an experimental intervertebral disk model, more IL-10-positive cells were observed in the degenerated disks than in the control disks, whereas the number of IL-6-labeled cells did not differ between sites or between control and experimental degenerated disks (Holm et al., 2009). Besides degenerative disk, IL-10 protein expression was markedly up-regulated in the paradiscal structures, including vertebral bone, vertebral-end plates, and spinal ligaments as well (Ahn et al., 2002). The anti-inflammatory IL-10 in intervertebral disk disease is probably increased as a result of the tight coupling of the pro-inflammatory arm of the local disk disease process with an anti-inflammatory regulatory arm of the response, which is necessary to prevent excessive stimulation and tissue destruction.

To date, a genetic association between ILs and LDD has not been sufficiently studied. Solovieva et al. (2006) reported that the gene polymorphism of IL-1 $\beta$, together with another gene encoding collagen, COL9A3, could modify the risk of dark nucleus pulposus and the joint occurrence of degenerative changes on MRI.

Currently, no study regarding the relationship between the SNPs of IL-10 and LDD was reported. Previous studies showed that the SNPs of IL-10 may be related to bone material density change and the development of osteoporosis. Genetic association analysis of Korean postmenopausal women revealed that IL-10 $-592 \mathrm{~A}>\mathrm{C}$ was associated with decreased bone mass (Park et al., 2004). Considering the important role of IL-10 in LDD, IL-10 polymorphisms may be an important genetic factor in LDD. Our study, for the first time, provided direct evidence to support this hypothesis.

The gene encoding IL-10 is located on chromosome 1 (1q31-1q32). The polymorphisms of $-1082 \mathrm{~A} / \mathrm{G},-819 \mathrm{~T} / \mathrm{C}$ and $-592 \mathrm{~A} / \mathrm{C}$ in the proximal region influence the transcription of IL-10 mRNA and IL-10 production (Reuss et al., 2002). The -1082 A allele confers a 2 -fold increase in transcriptional activity of the IL-10 promoter compared to the G allele in a B cell line, and the G-A polymorphism at position -1082 of the IL-10 promoter results in lower levels of the IL-10 protein (Rees et al., 2002). In contrast, the stimulation of lymphocytes in vitro showed that the GG genotype at -1082 of the IL-10 promoter is associated with a 1.3-fold increase in the IL-10 protein production compared to the AA genotype. In our study, we found that IL-10 mRNA was significantly higher in the GG genotype at -1082 than GA and AA, suggesting that the GG genotype may be associated with higher IL-10 production. Claudino et al. (2008) showed that a significantly lower level of IL-10 mRNA was observed in patients with the IL-10 -592 CA or AA genotype, compared to CC. In our study, a similar phenomenon was observed. The AA carriers had markedly lower IL-10 mRNA level, while the CC carriers had a significantly higher IL-10 mRNA expression, suggesting that A may be a detrimental allele for LDD. This was supported by the result of logistic regression analysis, which showed that the $\mathrm{AA}$ at -592 was an independent risk factor for $\mathrm{LDD}(\mathrm{OR}=1.68,95 \% \mathrm{CI}=1.23-3.46, \mathrm{P}=0.026)$.

Previous studies reported that the radiographic progression of LDD is influenced by variation in inflammatory genes. Polymorphisms in MMP3, tissue inhibitor of metalloproteinase-1 (TIMP1), and cyclooxygenase-2 (COX2), which encode enzymes that produce molecules involved in inflammatory pathways, were associated with radiographic progression of LDD (Valdes et al., 2005). This result suggests a role for genes regulating inflammatory path- 
ways in the radiographic progression of spine degeneration. However, in the present study, the genotype distributions of 3 loci of the IL-10 gene among subjects with different severity grades were similar (all $\mathrm{P}>0.05$ for SNPs at each locus), suggesting that the IL-10 promoter SNPs at $-1082 \mathrm{~A} / \mathrm{G},-819 \mathrm{~T} / \mathrm{C}$, and $-592 \mathrm{~A} / \mathrm{C}$ did not determine LDD severity.

Interestingly, the IL-10 mRNA expression in LDD was considerably inconsistent. In one study, IL-10 mRNA could only be found in 2 of $23(9 \%)$ human herniated disk samples when a sensitive real-time reverse transcription-PCR method was used (Ahn et al., 2002). However, another study disclosed that the clearest changes occurred with IL-10 mRNA, where modest changes occurred with TNF- $\alpha$ mRNA, but no clear changes occurred in IL- 6 mRNA in LDD cases compared to controls (Holm et al., 2009). In our study, due to ethical concerns, we did not collect disc samples from controls, so we did not analyze the difference in IL-10 mRNA between cases and controls.

Several limitations in this study need to be specified. Firstly, this study was a singlecenter cohort investigation on a relatively small scale, and thus, replication studies with large independent cohorts are suggested. Secondly, we have no disc samples from healthy controls due to ethical considerations, and thus, the comparison of IL-10 mRNA between cases and controls was not possible in this study. Instead, we analyzed only the IL-10 mRNA expression among different genotype carriers within cases. Thirdly, we did not detect the IL-10 protein expression. As IL-10 polymorphisms may be insufficient to clarify the complex interplays between a number of different genes controlling expression of IL-10, it will be ideal to directly examine the expression of IL-10 protein.

\section{ACKNOWLEDGMENTS} (\#2005y014).

Research supported by the Science and Technology Development Project of Fujian

\section{REFERENCES}

Ahn SH, Cho YW, Ahn MW, Jang SH, et al. (2002). mRNA expression of cytokines and chemokines in herniated lumbar intervertebral discs. Spine 27: 911-917.

Akyol S, Eraslan BS, Etyemez H and Tanriverdi T (2010). Catabolic cytokine expressions in patients with degenerative disc disease. Turk. Neurosurg. 20: 492-499.

Battie MC, Videman T and Parent E (2004). Lumbar disc degeneration: epidemiology and genetic influences. Spine 29: 2679-2690.

Claudino M, Trombone AP, Cardoso CR, Ferreira SB Jr, et al. (2008). The broad effects of the functional IL-10 promoter-592 polymorphism: modulation of IL-10, TIMP-3, and OPG expression and their association with periodontal disease outcome. J. Leukoc. Biol. 84: 1565-1573.

Hassett G, Hart DJ, Manek NJ, Doyle DV, et al. (2003). Risk factors for progression of lumbar spine disc degeneration: the Chingford Study. Arthritis Rheum. 48: 3112-3117.

Holm S, Mackiewicz Z, Holm AK, Konttinen YT, et al. (2009). Pro-inflammatory, pleiotropic, and anti-inflammatory TNF-alpha, IL-6, and IL-10 in experimental porcine intervertebral disk degeneration. Vet. Pathol. 46: 1292-1300.

Igarashi A, Kikuchi S, Konno S and Olmarker K (2004). Inflammatory cytokines released from the facet joint tissue in degenerative lumbar spinal disorders. Spine 29: 2091-2095.

Iguchi T, Kanemura A, Kasahara K, Kurihara A, et al. (2003). Age distribution of three radiologic factors for lumbar instability: probable aging process of the instability with disc degeneration. Spine 28: 2628-2633.

Kawaguchi S, Yamashita T, Yokogushi K, Murakami T, et al. (2001). Immunophenotypic analysis of the inflammatory infiltrates in herniated intervertebral discs. Spine 26: 1209-1214.

Kawaguchi S, Yamashita T, Katahira G, Yokozawa H, et al. (2002). Chemokine profile of herniated intervertebral discs 
infiltrated with monocytes and macrophages. Spine 27: 1511-1516.

Kurreeman FA, Schonkeren JJ, Heijmans BT, Toes RE, et al. (2004). Transcription of the IL10 gene reveals allele-specific regulation at the mRNA level. Hum. Mol. Genet. 13: 1755-1762.

Lalani I, Bhol K and Ahmed AR (1997). Interleukin-10: biology, role in inflammation and autoimmunity. Ann. Allergy Asthma Immunol. 79: 469-483.

Ma SL, Tang NL, Lam LC and Chiu HF (2005). The association between promoter polymorphism of the interleukin-10 gene and Alzheimer's disease. Neurobiol. Aging 26: 1005-1010.

Matsui H, Kanamori M, Ishihara H, Yudoh K, et al. (1998). Familial predisposition for lumbar degenerative disc disease. A case-control study. Spine 23: 1029-1034.

Park BL, Han IK, Lee HS, Kim LH, et al. (2004). Association of interleukin 10 haplotype with low bone mineral density in Korean postmenopausal women. J. Biochem. Mol. Biol. 37: 691-699.

Pye SR, Reid DM, Adams JE, Silman AJ, et al. (2006). Radiographic features of lumbar disc degeneration and bone mineral density in men and women. Ann. Rheum. Dis. 65: 234-238.

Rees LE, Wood NA, Gillespie KM, Lai KN, et al. (2002). The interleukin-10-1082 G/A polymorphism: allele frequency in different populations and functional significance. Cell. Mol. Life Sci. 59: 560-569.

Reuss E, Fimmers R, Kruger A, Becker C, et al. (2002). Differential regulation of interleukin-10 production by genetic and environmental factors - a twin study. Genes Immun. 3: 407-413.

Sambrook PN, MacGregor AJ and Spector TD (1999). Genetic influences on cervical and lumbar disc degeneration: a magnetic resonance imaging study in twins. Arthritis Rheum. 42: 366-372.

Scuderi GJ, Brusovanik GV, Anderson DG, Dunham CJ, et al. (2006). Cytokine assay of the epidural space lavage in patients with lumbar intervertebral disk herniation and radiculopathy. J. Spinal Disord. Tech. 19: 266-269.

Solovieva S, Lohiniva J, Leino-Arjas P, Raininko R, et al. (2006). Intervertebral disc degeneration in relation to the COL9A3 and the IL-1ss gene polymorphisms. Eur. Spine J. 15: 613-619.

Tworek D and Kuna P (2005). The role of interleukin 10 in allergic inflammation. Pol. Merkur Lekarski. 18: 125-128.

Valdes AM, Hassett G, Hart DJ and Spector TD (2005). Radiographic progression of lumbar spine disc degeneration is influenced by variation at inflammatory genes: a candidate SNP association study in the Chingford cohort. Spine 30: 2445-2451.

Woertgen C, Rothoerl RD and Brawanski A (2000). Influence of macrophage infiltration of herniated lumbar disc tissue on outcome after lumbar disc surgery. Spine 25: 871-875. 